\title{
ESTRUTURA FITOSSOCIOLÓGICA DA FLORESTA SEMIDECÍDUA DE ALTITUDE DO PARQUE MUNICIPAL DA GROTA FUNDA (ATIBAIA - ESTADO DE SÃO PAULO)'
}

\author{
Maria Thereza Grombone ${ }^{3}$ \\ Luis Carlos Bernacci ${ }^{2}$ \\ João Augusto Alves Meira Neto ${ }^{2}$ \\ Jorge Yoshio Tamashiro ${ }^{2}$ \\ Hermógenes de Freitas Leitão Filho
}

Recebidos em 5-8-89 Aceito em 10-6-90

RESUMO - Foi desenvolvido um estudo fitossociológico no Parque Municipal da Grota Funda, município de Atibaia, estado de São Paulo $\left(46^{\circ} 25^{\prime}\right.$ W e $23^{\circ} 10^{\prime}$ 'S). A região é montanhosa com uma variação de altitude de 900 a 1.400 metros. Ao longo de um gradiente de altitude foram marcadas 42 parcelas de $10 \times 10$ metros. Em cada parcela foram contados todas as árvores com perímetro a altura do peito $>15 \mathrm{~cm}$. O estudo foi desenvolvido de abril de 1987 a novembro de 1988 . No levantamento fitossociológico foram amostrados 1.076 indivíduos, pertecendo a 52 famílias, 92 gêneros e 132 espécies. De cada espécie são apresentados os parâmetros freqüência (absoluta e relativa), densidade (absoluta e relativa), dominância (absoluta e relativa) e índice do valor de cobertura. Os resultados mostram que as famílias mais importantes são Myrtaceae, Lauraceae, Euphorbiaceae, Apocynaceae e Mimosaceae e as espécies mais importantes são Machaerium nictitans, Aspidosperma olivaceum, Anadenanthera colubrina, Sebastiania edwalliana, Guapira opposita e Styrax pohlii. A floresta semidecídua de altitude é muito peculiar do ponto de vista florístico e fitossociológico representando um tipo de floresta que ocorre somente em regiões com mais de 1000 metros de altitude.

Palavras-chave: Fitossociologia, Florestas Semidecíduas de altitude.
ABSTRACT - A phytosociological survey was carried out in the Grota Funda Municipal Park, Atibaia Municipality, São Paulo State $\left(45^{\circ} 45^{\prime}-46^{\circ} 45^{\prime} \mathrm{W}\right.$ and $23^{\circ} 10^{\prime}-23^{\circ} 15^{\prime} S$ ). The region is mountainous, occurring from 900 to 1400 meters above sea level. A total of 42 quadrats, each $10 \times 10 \mathrm{~m}$, were plotted along an alti- tudinal gradient. In each sample, all trees with perimeter $\geqslant 15 \mathrm{~cm}$ at breast height were recorded. The study was done from April 1987 to November 1988. In the phytosociological survey, 1076 individuals were recorded, belonging to 52 fami-
1 - Auxílio para Pesquisa do CNPq - Proc. 403107/87.3/ZO/Fv.
2 - Departamento de Botânica - Instituto de Biologia, Universidade Estadual de Cam- pinas. Caixa Postal 6109 - 13081 - Campinas - São Paulo.
3 - Bolsista de Aperfeiçoamento do CNPq. Proc. no 820691/88.8. 
lies, 92 genera and 134 species. Phytosociological parameters of frequency (absolute and relative), density (absolute and relative), dominance (absolute and relative), importance value index and cover index are presented for all species. The results show that the most important families are Myrtaceae, Lauraceae, Euphorbiaceae, Apocynaceae and Mimosaceae and the most important species are Machaerium nictitans, Aspidosperma olivaceum, Anadenanthera colubrina, Sebastiania edwalliana, Guapira opposita and Styrax pohlii. The semideciduous, moutain forest is unique and represents a kind of forest that occurs only in regions above $1000 \mathrm{~m}$, with floristic and phytosociological particularities.

Key words: phytosociology, moutain forests, semideciduous.

\section{Introdução}

Estudos fitossociológicos são da máxima importância para a caracterização do papel exercido por cada espécie dentro da comunidade e também contribuem de forma decisiva na indicação dos estádios sucessionais e para uma melhor avaliação da influência de fatores de clima, solo e ação antrópica nas comunidades vegetais. Desta maneira, medidas de recuperação ambiental necessariamente devem ser precedidas de estudos desta natureza, em formações vegetais remanescentes, pois permitem indicar quais espécies são mais adequadas para cada estádio da recuperação do meio ambiente. Por outro lado, a maior ou menor abundância de determinadas espécies em determinados ambientes é muitas vezes de grande importância para caracterizar determinadas formações florestais. Neste caso também se enquadram as matas semidecíduas de regiões de altitude do sudeste do Brasil, que abrigam espécies exclusivas deste tipo de formação e várias outras que são caracteristicamente mais abundantes nesta vegetação (Meira Neto et al., 1989). Este trabalho objetiva contribuir para uma melhor elucidação destas formações, ainda precariamente conhecidas por alguns trabalhos fragmentados, quase sempre não envolvendo estudos fitossociológicos detalhados (Mattos et al., 1982; Dusen, 1955) ou com informações fitossociológicas mais detalhadas (Silva et al., 1989; Veloso, 1945) mas que não permitem ainda um perfeito entendimento desta fitocenose.

\section{Material e métodos}

O estudo foi realizado no município de Atibaia (46 $25^{\prime} \mathrm{W}$ e $23^{\circ} 10^{\prime} \mathrm{S}$ ) em uma área pertencente à municipalidade. O Parque Municipal da Fazenda Grota Funda, com área de 245 hectares que possui em sua quase totalidade cobertura florestal nativa bem preservada. O clima e os solos do local são descritos em trabalho anterior que trata da composição florística (Meira Neto et al.,1989). 
Para a obtenção de dados fitossociológicos o método empregado foi o de parcelas, sendo estas instaladas ao longo de um gradiente de altitude de 1100 a $1440 \mathrm{~m}$, mensurados com altímetro. As parcelas mediram $10 \times 10 \mathrm{~m}$, em número de 42 e nelas foram amostrados todos os indivíduos com PAP (perímetro a altura do peito) $>15 \mathrm{~cm}$ (DAP $>4,8 \mathrm{~cm}$ ) sendo todos etiquetados com plaquetas de alumínio numeradas. A altura das árvores foi estimada por comparação a uma tesoura de alta poda que media $6 \mathrm{~m}$. As árvores mortas e em pé que possuíam o PAP estabelecido também foram amostradas.

Todos os indivíduos amostrados tiveram seus ramos coletados em fase reprodutiva e/ou vegetativa, sendo posteriormente processades $c$ identificados no Herbário UEC.

A análise quantitativa foi feita através dos seguintes parâmetros fitossociológicos:

$\mathrm{DAi}=$ ni. $10000 / \mathrm{A} ; \mathrm{DRi}=100 .(\mathrm{ni} / \mathrm{N}) ; \mathrm{FAi}=100 .(\mathrm{Pi} / \mathrm{P}) ;$

$\mathrm{FRi}=100 .\left(\mathrm{FAi} / \sum_{\mathrm{J}=1}^{\mathrm{S}} \mathrm{Faj}\right) ; \quad \mathrm{DoRi}=100 . \quad(\mathrm{Gi} / \mathrm{G}) ;$

$\mathrm{IVIi}=\mathrm{DRi}+\mathrm{FRi}+\mathrm{DoRi}$ IVCi $=\mathrm{DRi}+\mathrm{DoRi}$. Onde: $\mathrm{ni}$ - número de indivíduos da espécie $\mathrm{i}$; $\mathrm{N}$ - número total de indivíduos; $\mathrm{A}$ - área amostrada em $\mathrm{m}^{2} ; 10.000$ - área em $\mathrm{m}^{2}$ de 1 hectare; $\mathrm{Pi}$ - número de parcelas com ocorrência da espécie i; $\mathrm{P}$ - número total de parcelas; $\mathrm{Gi}$ - área basal total da espécie i; G - área basal total; $\mathrm{S}$ - número total de espécies.

A análise dos dados foi feita através do programa FTTOPAC, desenvolvido pelo Prof. Dr. George John Shepherd do Departamento de Botânica, IB - UNICAMP, escritos em PASCAL e FORTRAN.

\section{Resultados e Discussão}

No estudo fitossociológico foram amostrados 1.076 indivíduos, pertencentes a 52 famílias, 92 gêneros e 132 espécies, conforme detalhado na Tabela 1. As 10 famílias mais abundantes perfazem $60,69 \%$ do número total de indivíduos, com a família Myrtaceae ocupando a primeira posição em $15,33 \%$, seguida de Euphorbiaceae com $8,36 \%$, existindo entre ambas uma considerável diferença de $6,97 \%$ (Figura 1). As demais famílias apresentam valores próximos entre si, com diferenças sempre menores que $3 \%$. Entre as espécies mais abundantes destacam-se algumas que não pertencem às famílias que ocupam as primeiras posições (Myrtaceae, Euphorbiaceae) (Figura 2). As 10 espécies mais abundantes integralizam, juntas, $30,5 \%$ do número total de indivíduos e algumas representam o total amostrado de suas respectivas famílias como é o caso de Guapira opposita, Styrax pohlii, Connarus regnellii e Prunus sellowii. 
Ao nível de espécies nota-se que nenhuma das 10 espécies mais freqüentes apresenta valores superiores a $60 \%$, não havendo portanto uma definição fisionômica a partir de apenas uma delas (Figura 3). Guapira opposita ê abundante (ocupando a $3^{\text {a }}$ posição) mas não muito freqüente na área, evidenciando uma distribuição contagiosa. Outras espécies como Casearia obliqua e Rollinia sylvatica não são muito abundantes, mas revelam uma expressiva área de distribuição, sendo relativamente freqüentes. As espécies Machaerium nictitans, Aspidosperma olivaceum, Sebastiania edwalliana, Connarus regnellii, Croton floribundus, Prunus sellowii e Cupania vernalis são freqüentes e abundantes.

A família que apresenta maior dominância relativa é Lauraceae $(16,23 \%)$, seguida de Mimosaceae $(8,41 \%)$, Myrtaceae $(8,25 \%)$, Euphorbiaceae $(7,41 \%)$ e Fabaceae $(7,38 \%)$ (Figura 4). Com relação à dominância por família dois padrões são claramente distintos:

a) Famílias que se destacam mais pela expressiva área basal de seus indivíduos - Lauraceae, Mimosaceae, Apocynaceae, Styracacea, Sapotaceae.

b) Famílias que se destacam pela área basal pouco expressiva de seus indivíduos, mas uma considerável abundância dos mesmos - Myrtaceae, Nyctaginaceae e Flacourtiaceae.

A família Euphorbiaceae apresenta um padrão misto, pois algumas espécies têm pequena área basal e outras grandes áreas basais.

A Figura 5, que ilustra as espécies de maior dominância relativa, revela novamente os mesmos padrões anteriormente apresentados, com duas espécies de pequena área basal individual e grande número de indivíduos (Guapira opposita e Sebastiania edwalliana) e as demais, todas árvores de considerável área basal individual, com indivíduos numerosos ou não. A Figura 6 apresenta a relação das famílias com maiores valores de importância (IVI). 


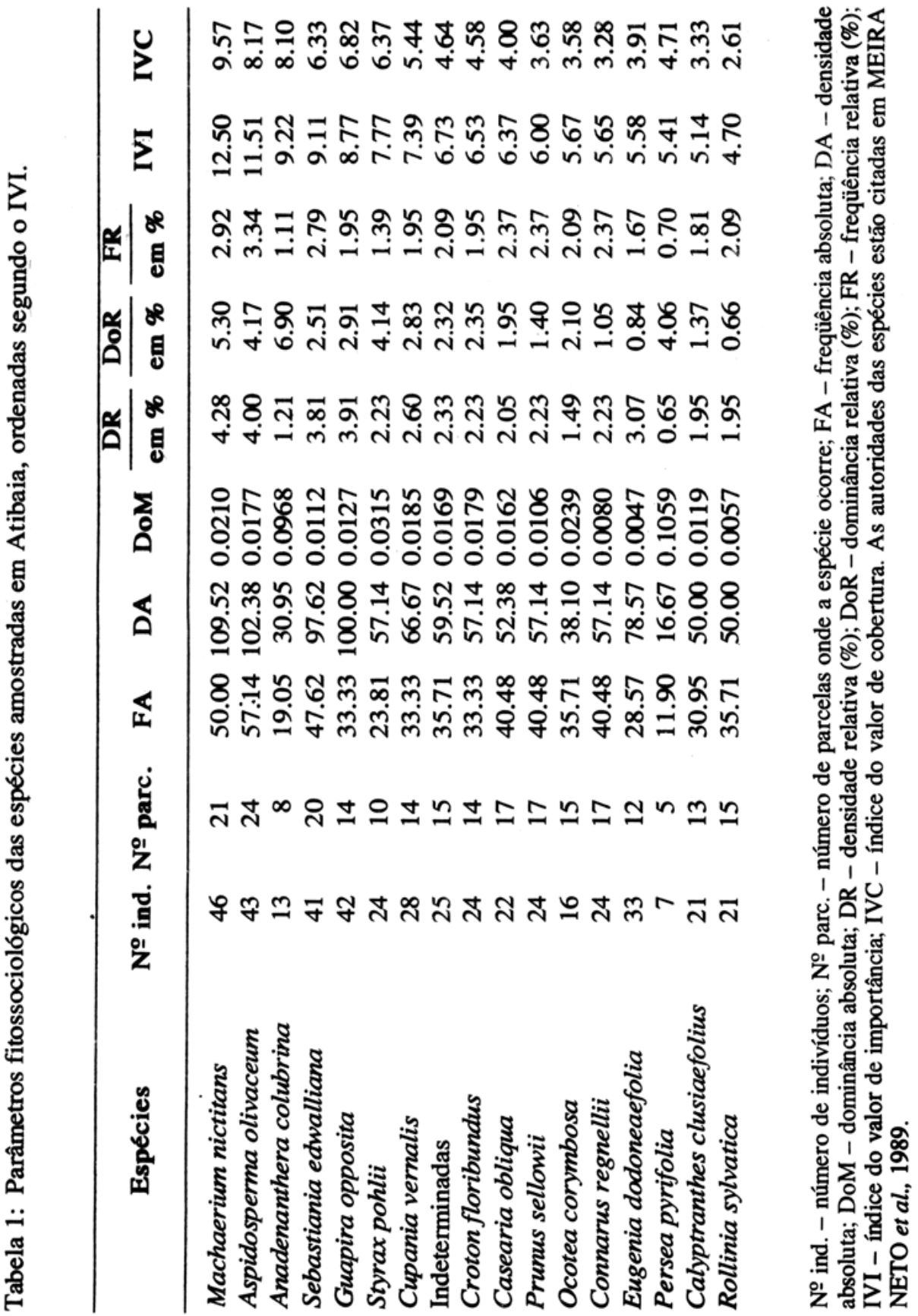




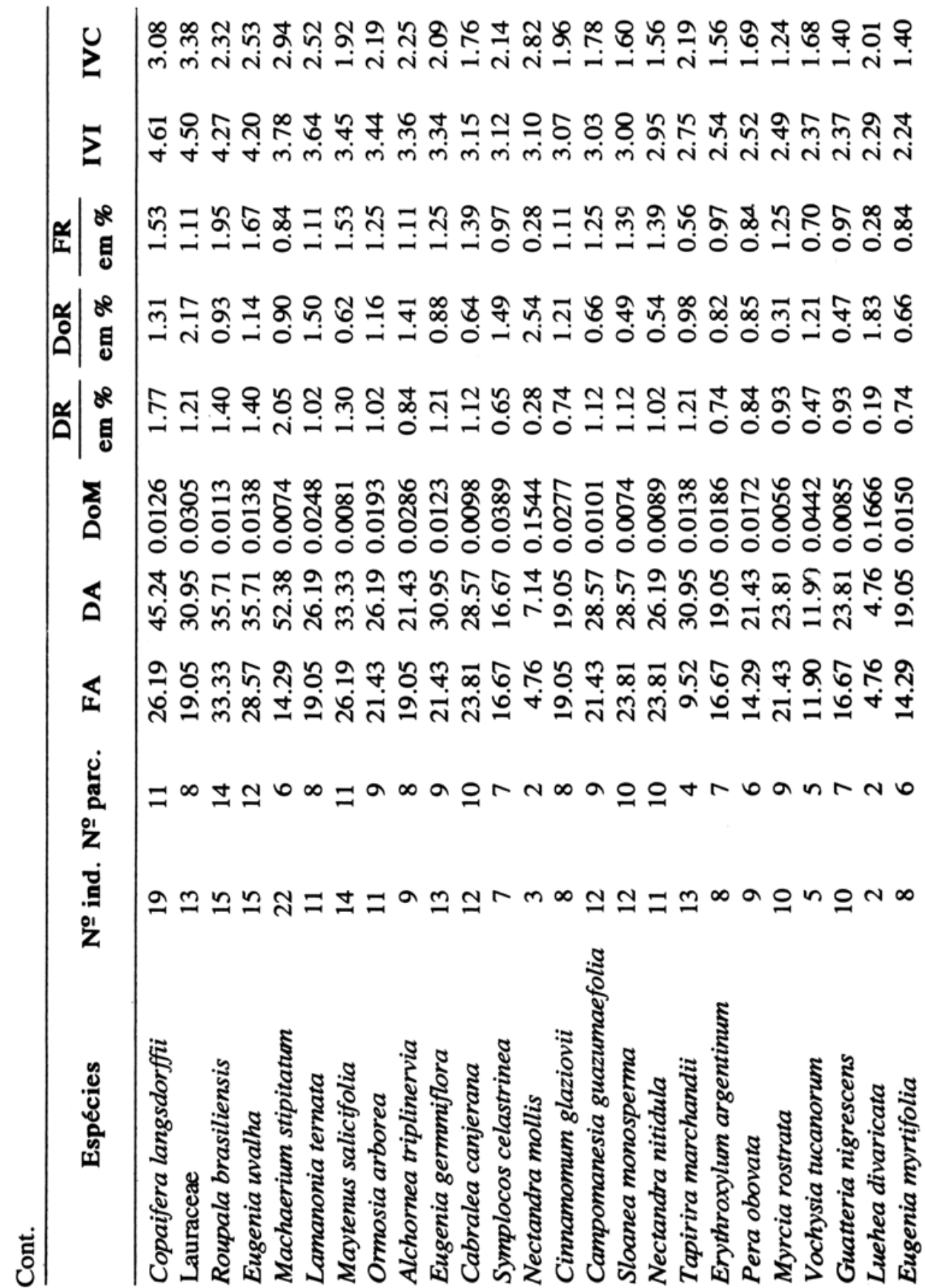




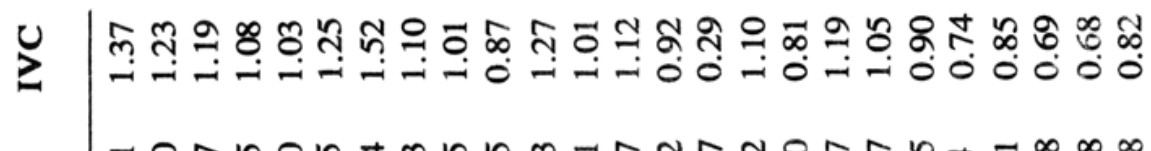

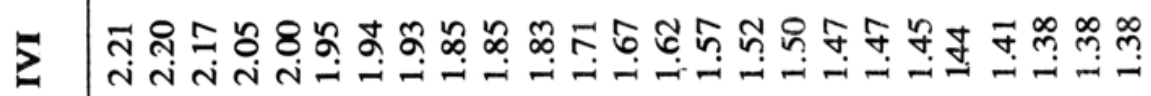

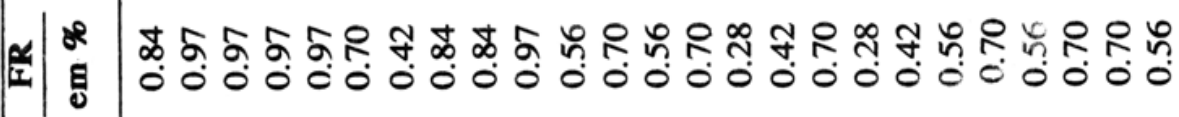

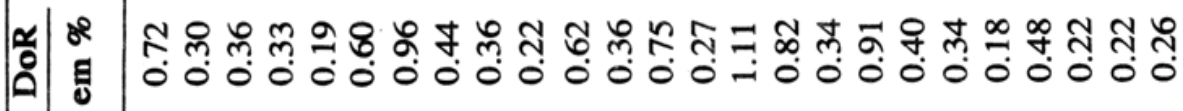

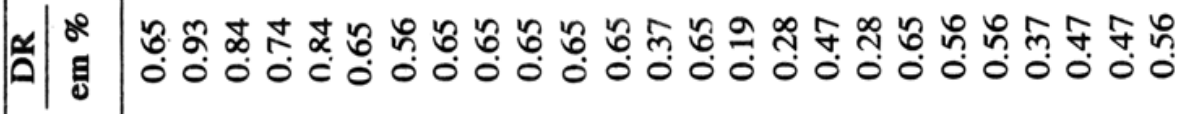

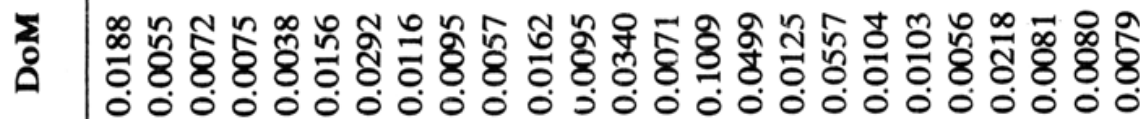

4 6

- $\quad$ กั่

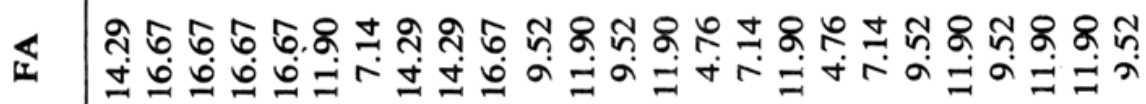

递

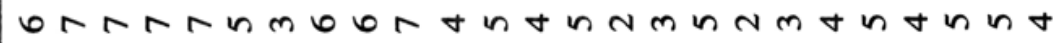

¿ृ

.

乙

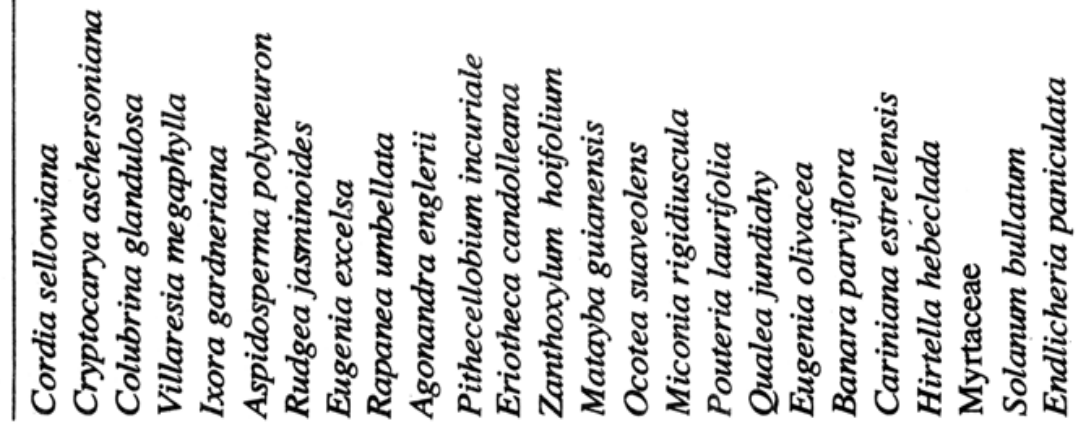




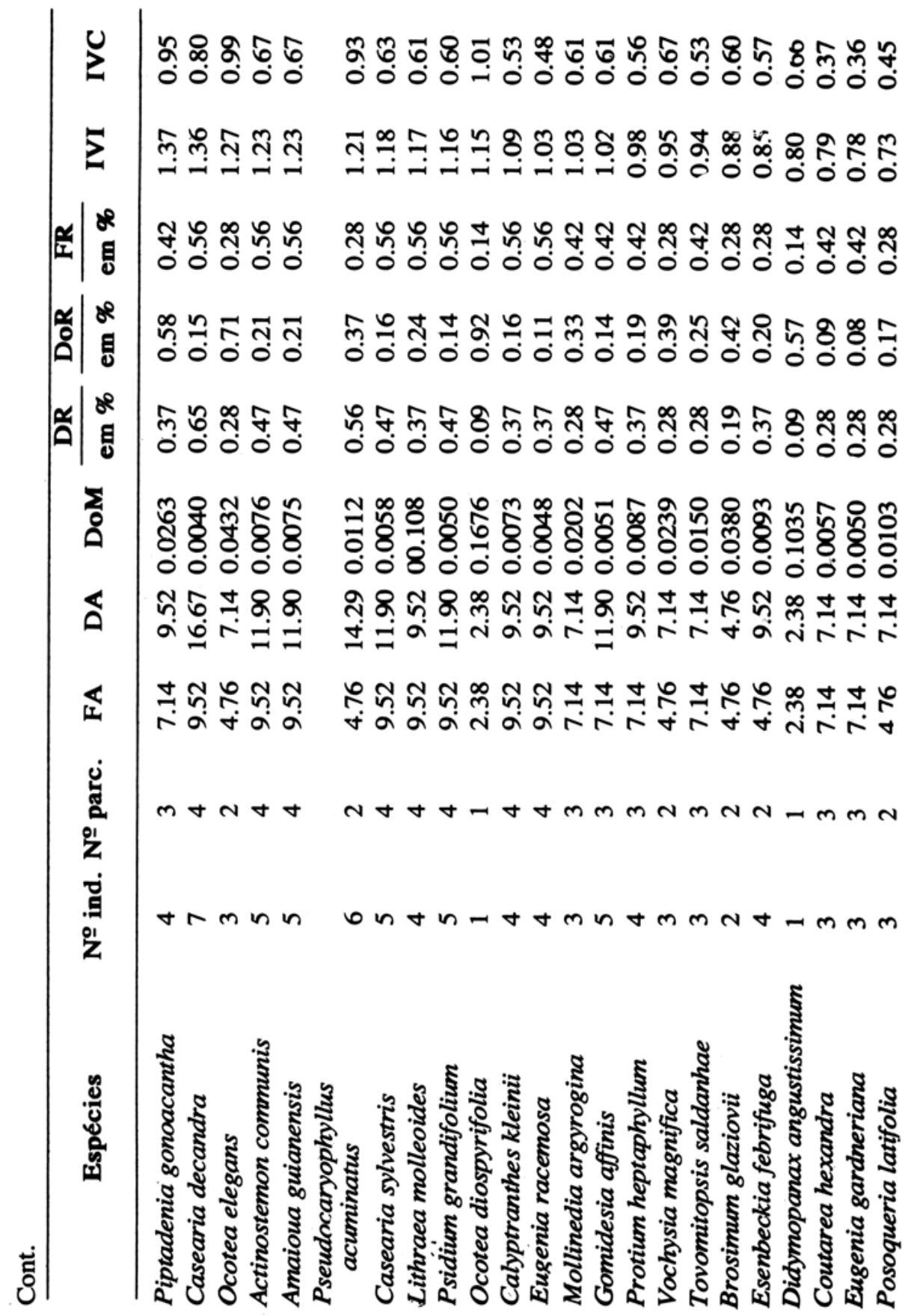




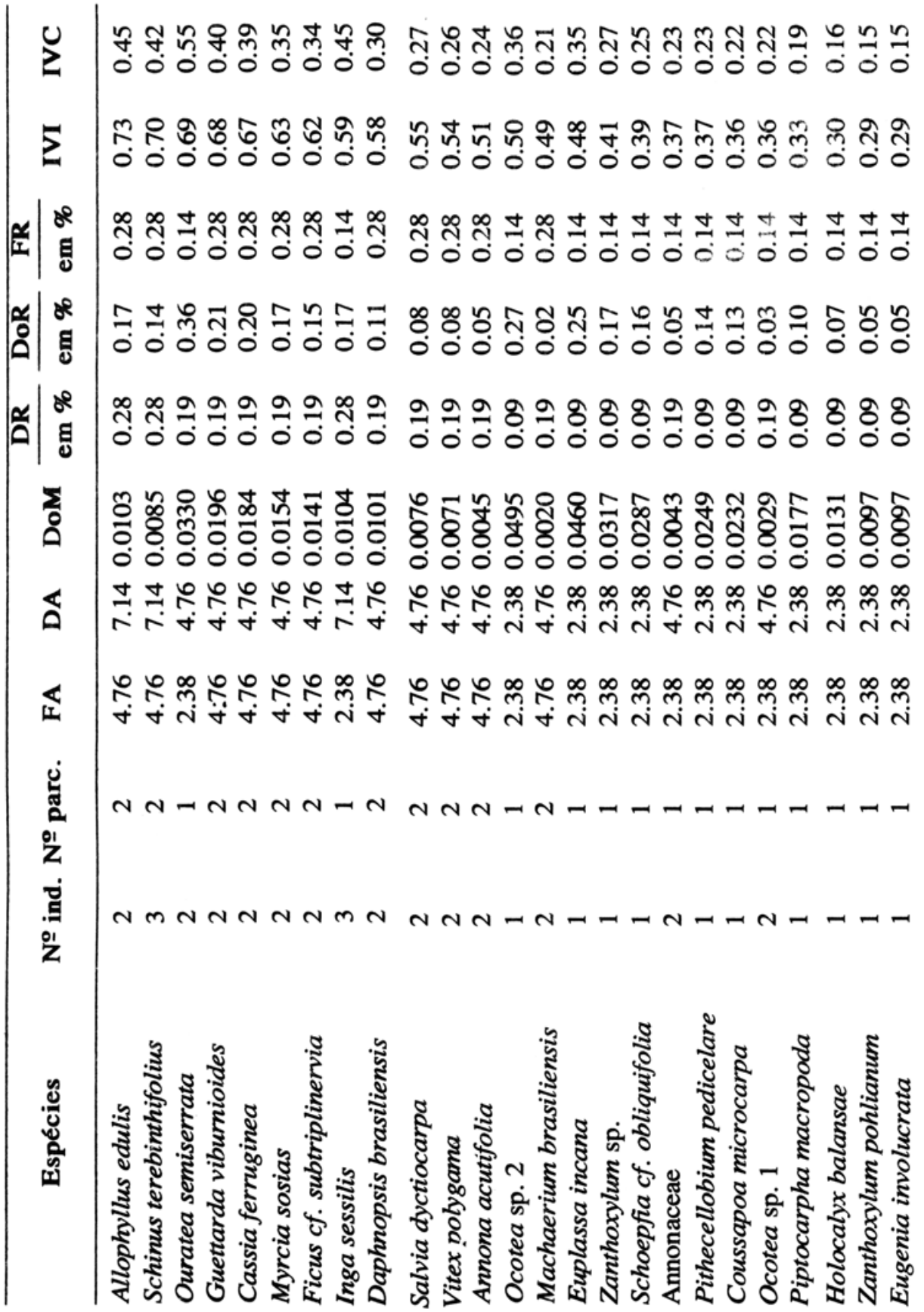




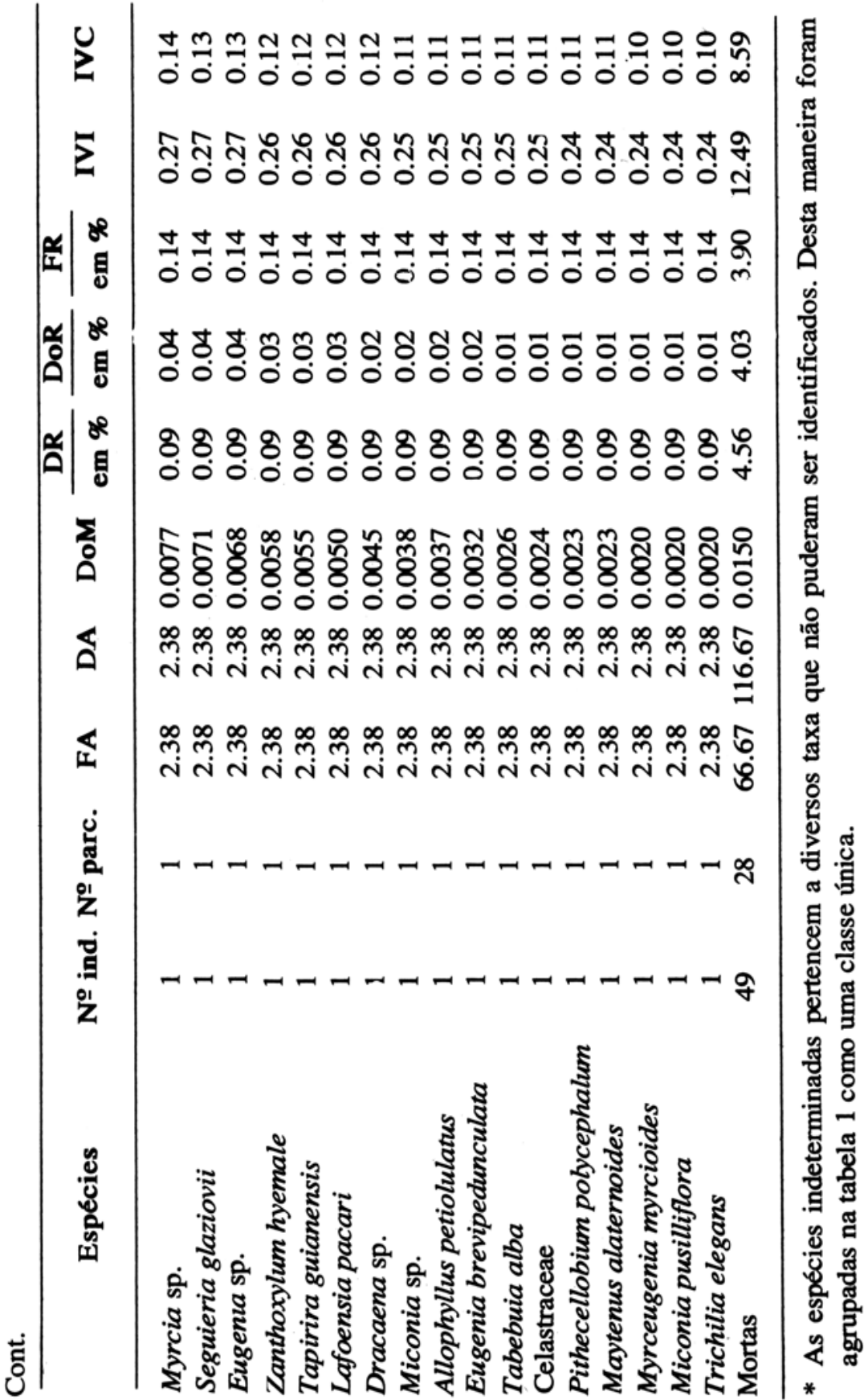




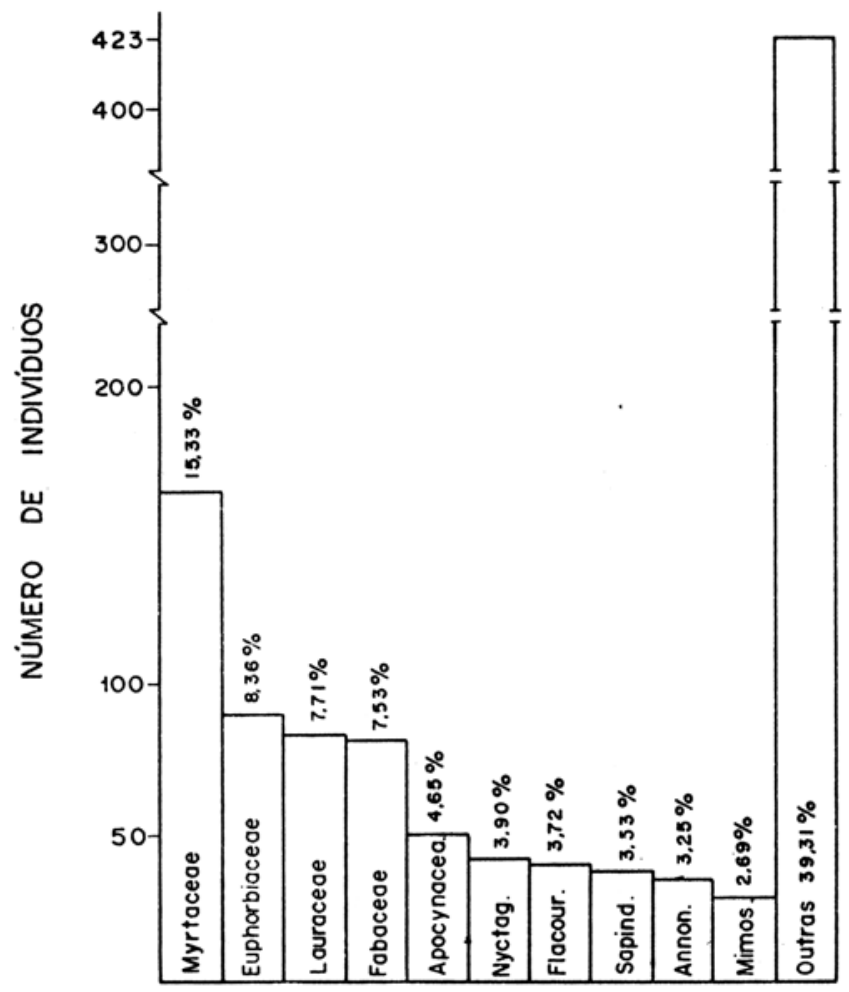

FAMILIA

Figura 1 - Familias com maior número de indivíduos expressos em porcentagem do número total de indivíduos amostrados. Nyctag. - Nyctaginaceae; Flacour. - Flacourtiaceae; Sapind. - Sapindaceae; Annon. - Annonaceae; Mimos. - Mimosaceae. 


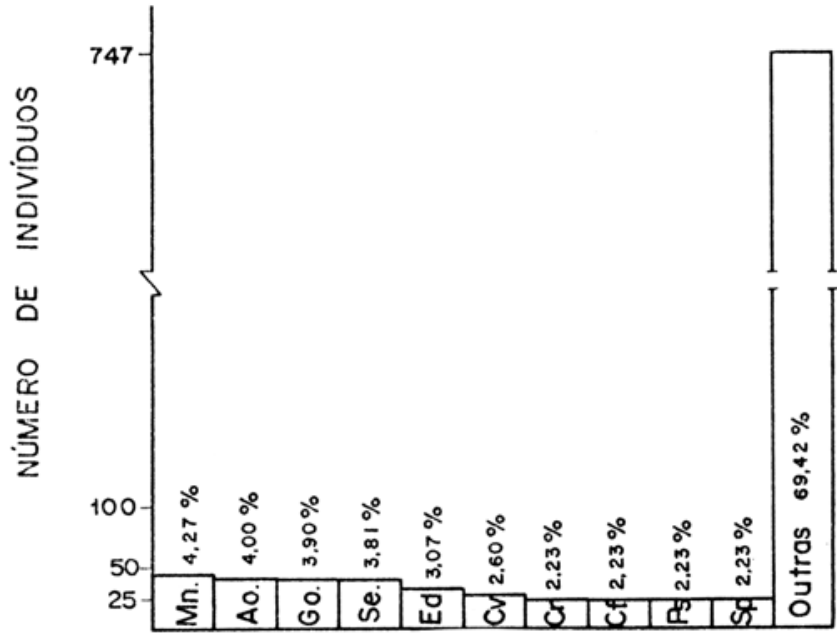

Figura 2

\section{ESPÉCIES}

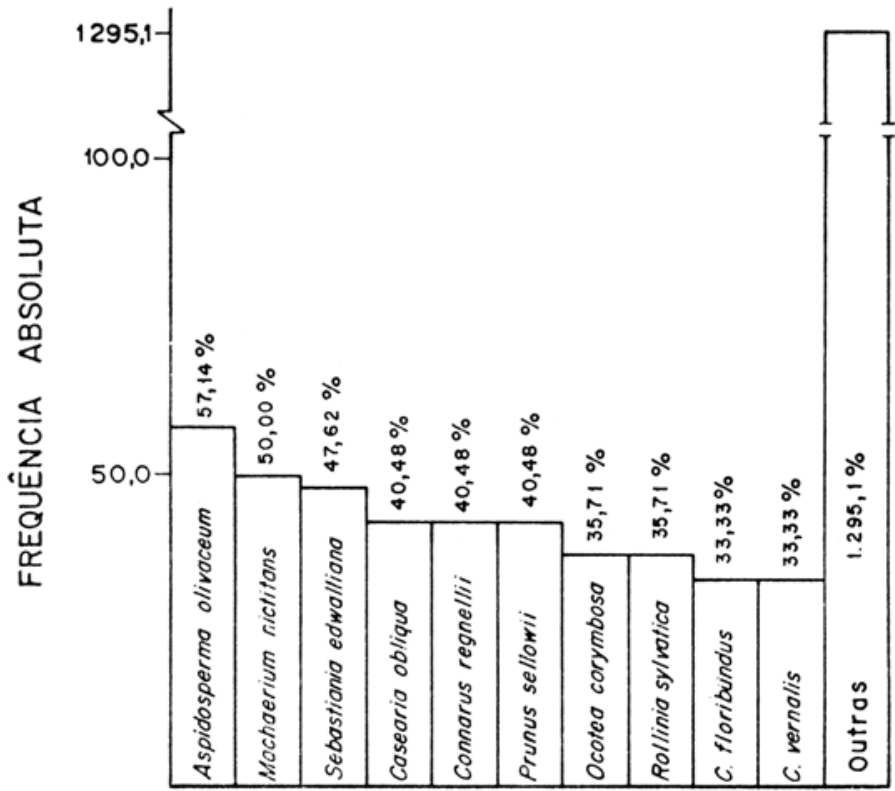

ESPÉCIES

Figura 3

Figura 2 - Espécies mais abundantes, expressas em porcentagem do número total de indivíduos amostrados. Mn - Machaerium nictitans; Ao - Aspidosperma olivaceum; Go - Guapira opposita; $\mathrm{Se}$ - Sebastiania edwaliana; $\mathrm{Ed}$ - Eugenia dodoneaefolia; $\mathrm{CV}-\mathrm{Cu}$ pania vernalis; $\mathrm{Cr}$ - Connarus regnellii; $\mathrm{Cf}$ - Croton floribundus; $\mathrm{Ps}-$ Prunus sellowii; Sp - Styrax pohlii.

Figura 3 - Espécies mais freqüentes na área amostrada. Para cada espécie é apresentado também o valor porcentual de ocorrência em relação ao total amostrado. 


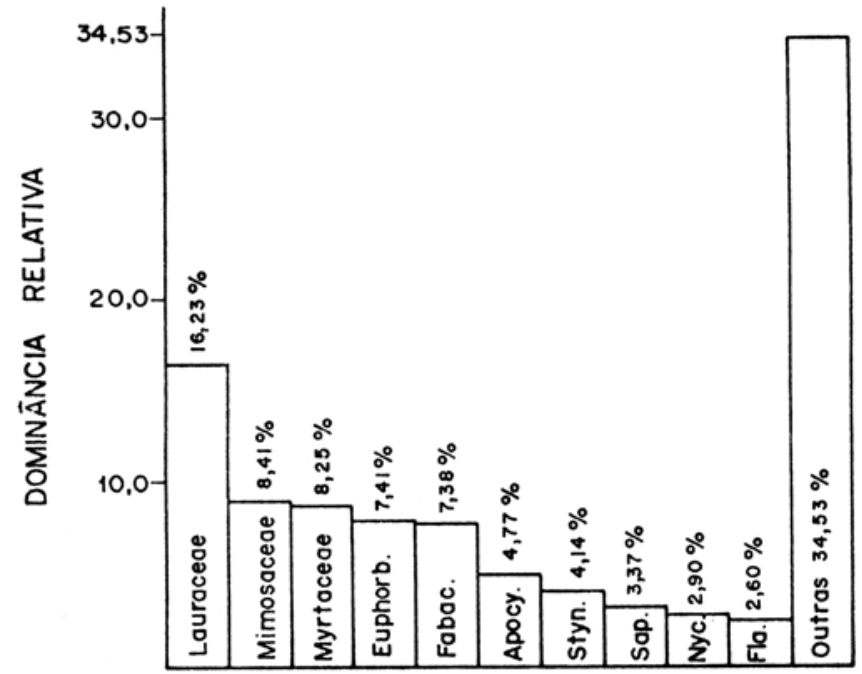

Figura 4

FAMILIAS

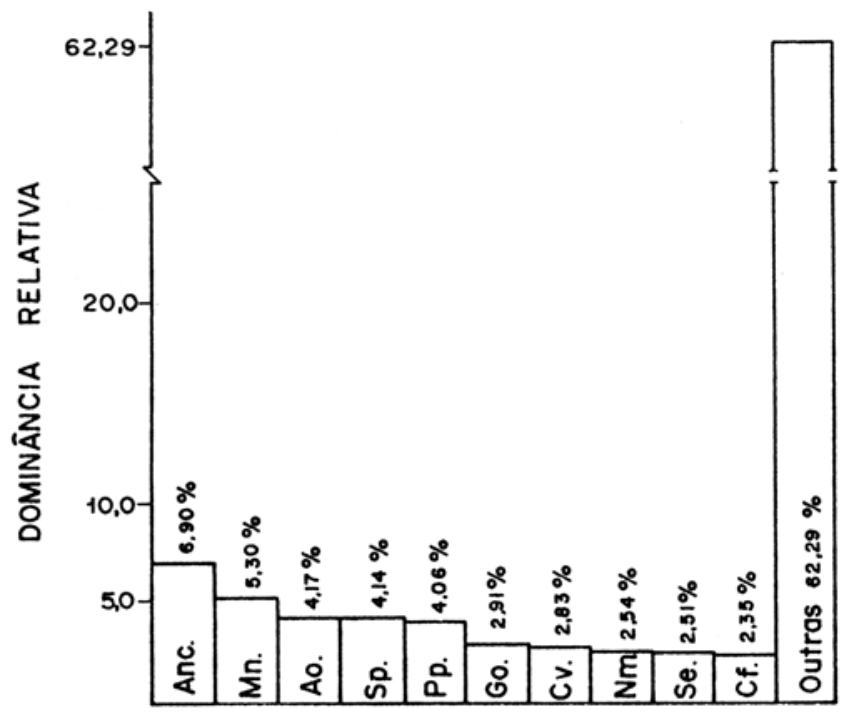

ESPÉCIES

Figura 5

Figura 4 - Relação das 10 familias que apresentam a maior dominância relativa. Euphorb. - Euphorbiaceae; Fabac. - Fabaceae; Apocy. - Apocynaceae; Styr. - Styracaceae; Sap. - Sapindaceae; Nyc. - Nyctaginaceae; Fla. - Flacourtiaceae.

Figura 5 - Espécies com maior dominância relativa na área amostrada. Anc - Anadenanthera colubrina; $\mathrm{Mn}$ - Machaerium nictitans; Ao - Aspidosperma olivaceum; $\mathrm{Sp}$ - Styrax pohlii; $\mathrm{Pp}$ - Persea pyrifolia; Go - Guapira opposita; $\mathrm{Cv}-$ Cupania vernalis; $\mathrm{Nm}-\mathrm{Nec}$ tandra mollis; $\mathrm{Se}$-Sebastiania edwalliana; Cf - Croton floribundus. 
A Figura 8 apresenta a relação das famílias com maiores valores de cobertura. A comparação destas duas figuras revela que as familias são as mesmas, com alterações em algumas posições em função da maior ou menor expressão dos parâmetros fitossociológicos considerados. Desta maneira, a família Myrtaceae, com um expressivo número de indivíduos de porte relativamente baixo e distribuídos em toda a área amostral é a primeira colocada em importância, mas ocupa a segunda posição em relação ao índice de valor de cobertura, que não considera os valores de freqüência relativa.

A comparação das informações das Figuras 6 e 8 revela que a região de Atibaia apresenta uma composição florística que se enquadra dentro dos padrões das matas semicaducifolias (Leitão Filho, 1982; 1986) com expressiva representatividade das famílias Myrtaceae, Lauraceae, Euphorbiaceae, Fabaceae. Algumas famílias muito comuns nas matas semicaducifolias (Meliaceae e Rutaceae) são raras na região de Atibaia (Matthes, et al., 1988; Pagano et al., 1987a, 1987b: Martins, 1979; Cesar, 1988). Este fato indica que embora com claras afinidades com as matas semicaducifolias a mata da região de Atibaia apresenta uma estrutura fitossociológica particular.

As Figuras 7 e 9 relacionam respectivamente as espécies com maiores índices de valor de importância (IVI) e de cobertura (IVC). A comparação entre as duas figuras revela que as espécies mais importantes e de maior valor de cobertura são as mesmas, com alterações da posição de Sebastiania edwalliana que é uma espécie de pequena área basal, mas muito abundante. Novamente, se compararmos a relação das espécies das Figuras 7 e 9 com as espécies mais importantes e de maior valor de cobertura nos vários estudos referidos de matas semicaducifólias no estado de São Paulo vamos observar que, sem nenhuma excessão, as espécies mais importantes em Atibaia não ocuparam posição de destaque em outros estudos fitossociológicos. Por outro lado, comparando-se os dados de Atibaia com o estudo de Rodrigues (1986) para a mata de altitude da Serra do Japi as semelhanças são bem maiores, ao ponto de haver em comum 4 espécies das 10 mais importantes (IVI) de cada floresta ( $\mathbf{M a}$ chaerium nictitans, Guapira opposita, Cupania vernalis e Prunus sellowii).

A evidência destes fatos permite concluir que a denominação das florestas de Atibaia de matas semicaducifolias de altitude é necessária e marca um fato biológico concreto. Evidencia ainda o valor de estudos florísticos e fitossociológicos na correta interpretação da fitogeografia, ressaltando inclusive as interrelações das várias formações florestais e também caracteriza que este tipo florestal deve ser considerado como uma formação individualizada, com reflexos na fauna e em toda a dinâmica do ecossistema. 


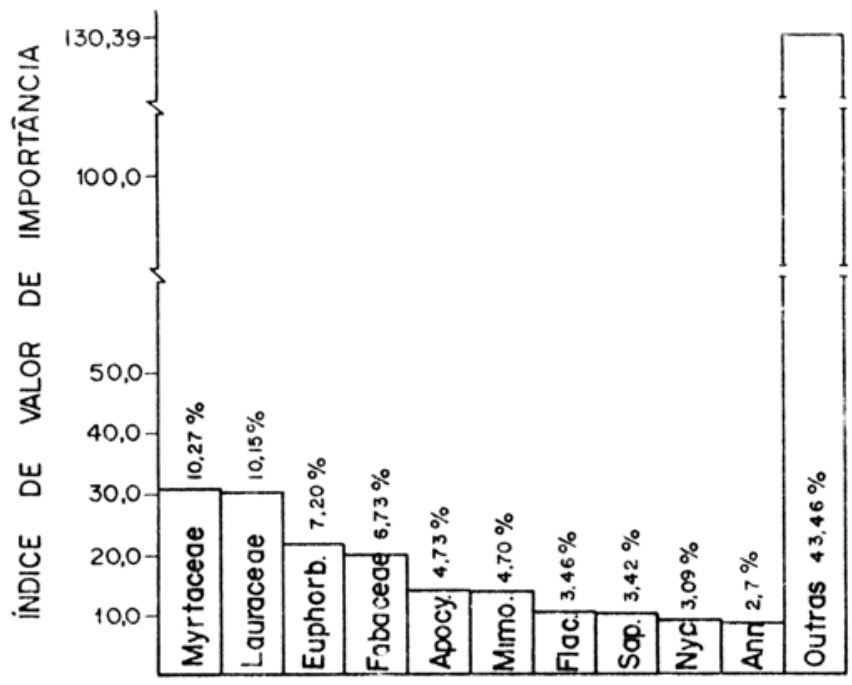

FAMILIAS
Figura 6

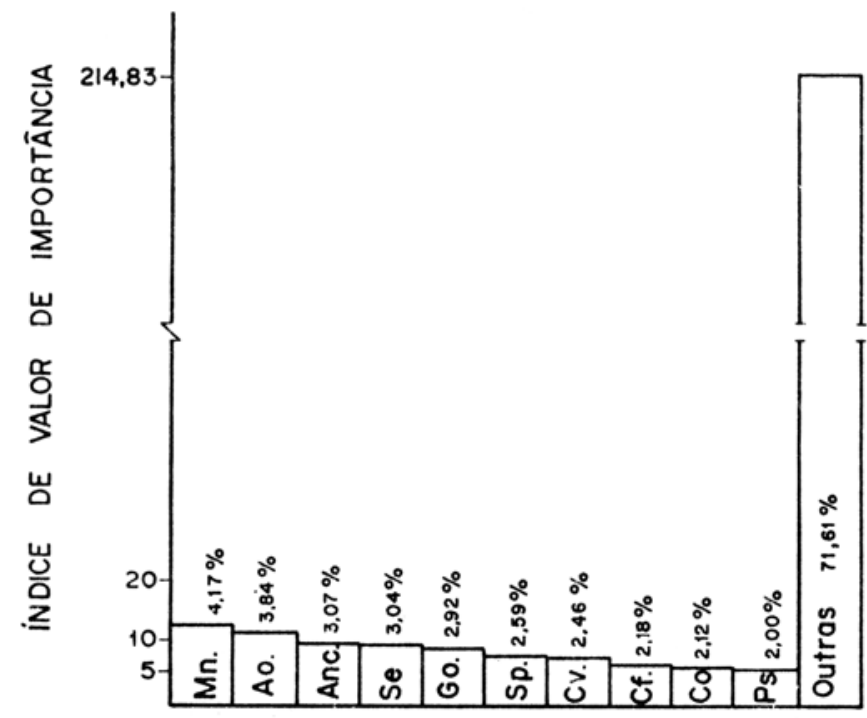

ESPÉCIES

Figura 7

Figura 6 - Relação das famílias que apresentam os maiores índices de Valor de Importância (IVI). Euphorb. - Euphorbiaceae; Apocy. - Apocynaceae; Mimo. - Mimosaceae; Flac. - Flacourtiaceae; Sap. - Sapindaceae; Nyc. - Nyctaginaceae; Ann - Annonaceae.

Figura 7 - Relação das espécies com maiores índices de Valor de Importância (IVI). Mn - Machaerium nictitans; Ao - Aspidosperma olivaceum; Anc - Anadenanthera colubrina; $\mathrm{Se}$ - Sebastiania edwalliana; Go - Guapira opposita; $\mathrm{Sp}$ - Styrax pohlii; $\mathrm{Cu}-$ Cupania vernalis; Cf - Croton floribundus; Co-Casearia obliqua; Ps - Prunus sellowii. 


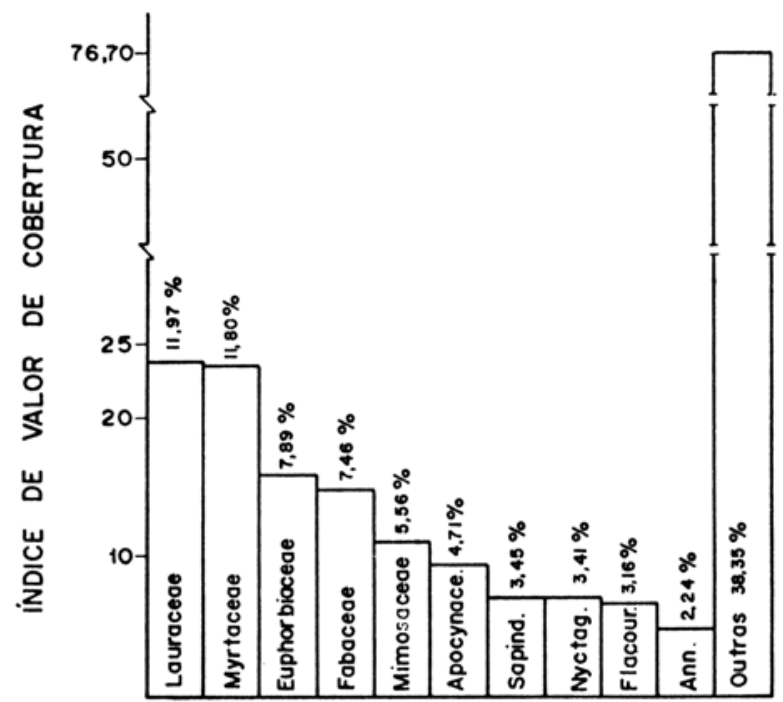

FAMILIAS

Figura 8

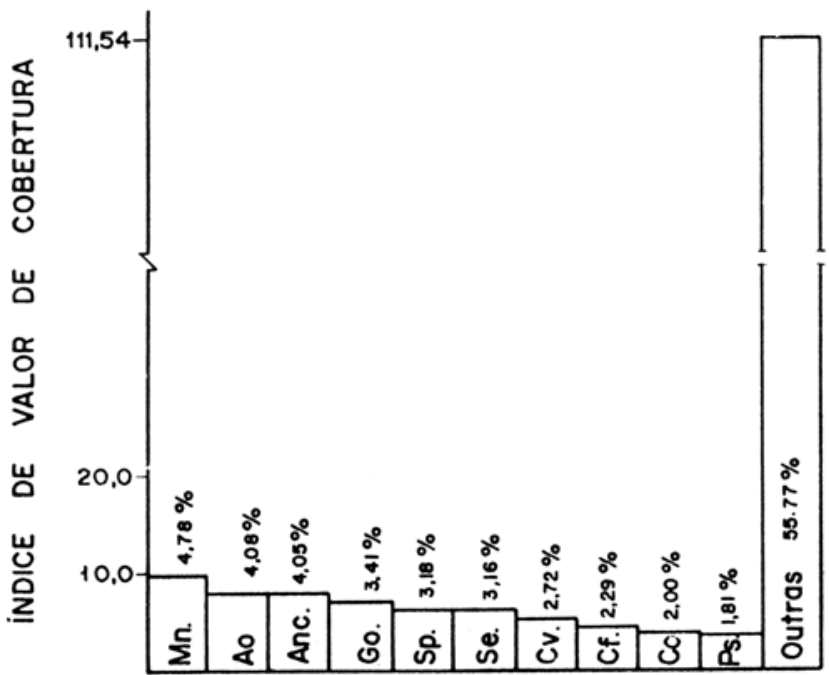

ESPÉCIES

Figura 9

Figura 8 - Relação das famílias com maiores índices de Valor de Cobertura (IVC). Apocynace. - Apocynaceae; Sapind. - Sapindaceae; Nyctag. - Nyctaginaceae; Flacour. Flacourtiaceae; Ann. - Annonaceae.

Figura 9 - Relação das espécies com maiores índices de Valor de Cobertura (IVC). Mn Machaerium nictitans; Ao - Aspidosperma olivaceum; Anc - Anadenanthera colubrina; Go - Guapira opposita; Sp - Styrax pohlii; Se - Sebastiania edwalliana; Cv - Cupania vernalis; Cf - Croton floribundus; Co - Casearia obliqua; Ps - Prunus sellowii. 


\section{Agradecimentos}

Os autores desejam manifestar seu melhor agradecimento ao senhor Dr. Gilberto Santana, Prefeito Municipal da Estância de Atibaia, engenheiro-agrônomo Carlos Alberto de Aquino e veterinária Criseida Martins Costa de Aquino, da Secretaria de Planejamento da Prefeitura Municipal da Estância de Atibaia pelo apoio, amizade e facilidades logísticas concedidas e ao senhor Luiz Albino, funcionário da Prefeitura Municipal pelo apoio nos trabalhos de campo.

\section{Referências Bibliográficas}

CESAR, O, 1988. Composiçâo florística, fitossociologia e ciclagem de nutrientes em mata semidecídua (Fazenda Barreiro Rico, Município de Anhembi, SP). Tese de Livre Docência. Universidade Estadual Paulista, Rio Claro.

DUSEN, P. K. H. 1955. Contribuições para a flora do Itatiaia. Parque Nacional do Itatiaia, Boletim 4:1-91.

LEITÃO FILHO, H. F. 1982. Aspectos taxonômicos das florestas do estado de São Paulo. Silvicultura em São Paulo 16(1):197-206.

LEITÃO FILHO, H. F. 1986. Considerações sobre a florística de florestas tropicais do Brasil. Anais da Mesa Redonda sobre a conservação "in situ" de florestas tropicais :1-26. Piracicaba, SP.

MARTINS, F. R. '1979. O método de Quadrantes e a fitossociologia de uma floresta residual do interior do estado de São Paulo. Tese de Doutorado. Universidade de São Paulo, São Paulo.

MATTHES, L. A. F., H.F. LEITÃO FILHO \& F.R. MARTINS. 1988. Bosque dos Jequitibás (Campinas, SP): Composição florística e estrutura fitossociológica do estrato arbóreo. Anais do V Congresso da Sociedade Botanica de São Paulo: p.55-76.

MATTOS, J. R. \& N.F. MATTOS. 1982. Contribuição ao conhecimento da flora do Parque Estadual de Campos do Jordão, SP. Silvicultura em São Paulo 16(1):647-662.

MEIRA NETO, J. A. A., L.C. BERNACCI, M.T. GROMBONE, J.Y. TAMASHIRO \& H.F. LEITÃO FILHO. 1989. Composição florística da mata semidecídua de altitude do Parque Municipal da Grota Funda (Atibaia - Est. São Paulo). Acta Bot. Bras. 3(2):51-74.

PAGANO, S. N. \& H.F. LEITÃO FILHO. 1987. Composição florística do estrato arbóreo de mata mesófila semidecídua, no município de Rio Claro (Estado de São Paulo). Revista. Bras. Bot. 10(1):37-47.

RODRIGUES, R. R. 1986. Levantamento florístico e fitossociológico das matas da Serra do Japí, Jundiai, SP. Dissertação de Mestrado. Universidade Estadual de Campinas, Campinas. 
SILVA, A. F., F.R. MARTINS \& H.F. LEITÃO FILHO. 1989. Composição florística da vegetação arbórea da Reserva Florestal professor Augusto Ruschi, São José dos Campos, SP. In. Resumos do $40^{\circ}$ Congresso Nacional de Botânica, Cuiabá.

TAMASHIRO, J. Y., R. RODRIGUES, \& G.J. SHEPHERD. 1986. Estudo florístico e fitossociológico da Reserva da Mata de Santa Genebra, Campinas, São Paulo. Relatório de Pesquisa, Fundação de Amparo à Pesquisa do Estado de São Paulo. (Inédito)

VELOSO, H. P. 1945. As comunidades e as estações botânicas de Teresópolis, Estado do Rio de Janeiro. Bolm. Mus. Nac. Botânica, 3:1-95. 